Open Access

\title{
'We are connected, but constrained': internet inequality and the challenges of millennials in Africa as actors in innovation
}

\author{
A. Victor Counted ${ }^{1,2^{*}}$ and Joyce O. Arawole
}

\author{
* Correspondence: VC@tmafrica.net \\ ${ }^{1}$ Third Millennium Africa Project, \\ Washington DC, USA \\ ${ }^{2}$ Research Fellow, PRACTMAUS, \\ Stellenbosch University, \\ Stellenbosch, South Africa
}

\begin{abstract}
One of the biggest news stories in the past decade has been the increasing impact of the internet and information technology on young people, from first-generation mission countries in North America and Western Europe to the global south — particularly in Africa. This advancement has fueled the growth of a "connected" and "plugged in" cohort of young people known as millennials, who are utilizing this medium to improve their social status and create potential for economic and professional growth. However, while the Internet has created opportunities for growth and development on the continent, many online platforms and services continue to restrict full access to certain parts of the global south. Hence, in some African countries, for example, opportunities for scaling innovation and development can be very difficult to access. Consequently, as our daily activities sync with technology, concerns over access to the Internet economy and the undue restrictions over internet services persist. Using the storytelling research methodology, this paper seeks to highlight why geo-restrictions and regional lockouts over internet-related services seem to be a major challenge for millennials in Africa, who are actors in innovation by virtue of their contribution to the growth of the internet technology. We argue that this enforced regional lockout not only deflates the productivity and creativity of African millennials, but also points to a functionalist view of internet inequality constituted through the "divides" of accessibility, censored participation, and acceptability in the internet economy. Understanding the staggering nature of this problem would require telling the stories of young internet entrepreneurs and innovators in Africa, who continue to be marginalized while investing and contributing to the internet economy.
\end{abstract}

Keywords: African millennials, Usage access, Narrative inquiry, Storytelling, Internet inequality, Digital development, Internet usage policy

\section{Background}

In February 2010, the Pew Research Forum came out with a comprehensive survey conducted in association with the PBS documentary series on millennials. In their research findings, millennials, a demographic cohort following Generation X (Horovitz 2012), were summarized as being confident, connected, and open to change (Pew Research 2010). Periodic events and trends, in this case, their technological exceptionalism, have left a particularly deep impression on this social generation, which then shapes their emerging identities. Thus these imprints stay with them as they move

\section{Springer}


through their life cycle (cf. Howe and Strauss 1991, 1997). Ultimately, technological exceptionalism is not just about the gadgets-it is the way millennials have fused their social lives into them. For example, three-quarter of millennials have created a profile on a social networking site, compared with half of Xers, $30 \%$ of Boomers, and $6 \%$ of Silents (cf. Pew Research 2010). There are big generation gaps, as well, in using wireless technology, playing video games, and posting self-created videos online.

To a large extent, African teens and twenty-somethings, even those in their early thirties, who are making the passage into adulthood at the start of the third millennium, have begun to fuse their social lives into technology. Besides, if technological exceptionalism truly differentiates the millennial generation from other generations-as we assume that Africa's teens and twenty-somethings are the millennials of Africa-what effect can technology and its associated systems have on Africa's millennial generation? And to what extent can millennials contribute to development in Africa? We take the risk of using the Americanized constructed term "millennial" to equally refer to young Africans within the millennial age-group. Arguably, Africa's young social generation may not have the same identity "parallels" as their American counterparts; which, of course, requires further investment in research. Hence, when we refer to African millennials in this article, we only mean young Africans who are between the millennial age bracket and born between 1982 and 2001 (cf. Howe and Strauss, 1991; Counted 2016b).

We now turn to our primary research question which is constructed as follows: Why are geo-restrictions and regional lockouts on internet-related services a major challenge for millennials in Africa and how do these enforced restrictions hinder Internet-fueled developments in Africa?

According to the Global Information Technology Report released in 2015, nearly half of the world's population now has access to high-speed broadband connection, totalling 3.4 billion in 2014 (Pepper and Garrity 2015). This access has contributed to innovation and economic growth in various regions of sub-Saharan Africa including Mauritius, Seychelles, South Africa, Nigeria, Rwanda, Kenya, and Cape Verde-scaling past that of the Middle East and North Africa. Furthermore, providing evidence of increased opportunities for investments to leverage new business models and services for continued growth and development (cf. Pepper and Garrity 2015).

Tremendous opportunities exist for tech-savvy millennials, with a positive outlook for the future. Although internet connectivity is rapidly growing, and penetration within many regions is still lacking, young Africans are claiming their spots in the internet economy (Kalan 2013). To date, there are vast number of internet hubs and business incubators that exist for young people to connect and innovate, as they develop tech-driven start-ups (Everett 2014), create online forums, networks, and blogs (Kalan 2013) - proving that the African youth and millennials in general are hungry for content, connectivity and change (cf. Kalan, 2013). However, while being connected has significantly impacted the continent, imposed restrictions and limited access to varied online platforms and services that come with usage access in many instances, continue to be restricted.

Therefore, since African millennials not only access and engage the internet technology through fading internet cafés, incubators, and increasing mobile access, concerns over the kind of opportunities such platforms provide become increasingly domineering 
as research further points that mobile internet usage in Africa is among the highest, with an estimate of one billion phones by 2016, with smartphone sales surpassing that of computers four to one (cf. Kalan, 2013). As it seems, innovation and the penetrated use of wireless technology on a daily basis in Africa has inspired a new breed of innovators who are developing life-saving applications, content, and platforms used to improve the standard of living (Jung et al. 2001: 512). The surge behind these inventions is determined by the opportunities available to create new ideas. And to a point, technological change and generational change often go hand in hand. This is exemplified in the story of African millennials and their embrace of all things digital (Heaven and Turriby 2003), as they try to put themselves at the frontlines of internet-fuelled development, even through unfair restrictions in the internet ecosystem.

\section{Internet diffusion and internet inequality in Africa}

The Internet is the fastest diffusing innovation to date (Dholakia et al. 2003: 7-12). To illustrate, it took just 10 years for it to reach $50 \%$ of American homes, compared to 52 years with electricity and 71 years with the telephone (Thierer 2000:83). Fifty million users were counted just within 2 years, compared to 38 years for radio and 13 years for television (Bell and Tang 1998: 8). As of 1999, the number of Internet users increased by one million every single month (McLaren 1999). While there are predictable challenges which center around having more affordable and widespread access and usage of the internet on the continent, connectivity is definitely in motion in many African countries, according to Nicholas Seidler (2013). Hence, debates have shifted to other more pressing issues gravitating around the all-important question: once you are connected, what are you able to do with it? Seidler (2013) expresses that,

The mere fact of being connected doesn't guarantee one will be able to innovate or able to freely share information and ideas: These abilities require an enabling Internet environment, one that is based on openness and without excessive restrictions on online activities (Seidler 2013:@3)

According to the State of the Internet Report in 2000 by the US Internet Council, "Internet diffusion in Africa has been hampered by factors such as poverty, low computer penetration, illiteracy, lack of trained personnel, disinterest, corruption, identity theft, and a failure to understand the benefits of Internet access" (Dholakia et al. 2003: 43). Worldwide, there is a modest correlation between economic atmosphere, information access, and the democratic political environment (Howard et al. 2010:110). It has been difficult to relate policy interventions with improvement in the diffusion or distribution of information technology within or between countries (Howard et al. 2009:208-219; Howard et al. 2009:1159-1169). And while some researchers have worked on the global Internet inequality by developing quantitative measures, much less work has been done on developing benchmarks for measuring the internet divide within countries. However, since the 9/11 attack on the United States, banks and online payment processors have changed their policies and terms of use (Onodu 2013:92). Some countries are not "supported online" as part of the ongoing but never ending reforms in the financial sector, while others are able to engage actively in its use. This shows a breach of fairness. Why would populations of a particular region have full 
access to information and communication technologies (ICTs) while others are denied access?

Although, the number of millennials who report positive impacts about the internet have grown, equally, the sheer size of millennials in Africa who are dissatisfied with policy-related issues having to do with internet usage and access also continue to increase. Even with the numerous opportunities available in the internet economy (offering narrow social and economic inequalities, supporting individual's wealth creation, and achieving the broader development goals of the community, cf. DOTForce 2001: $3)$, there still appears to be geographical limitations with communication technologies that people from poor societies have access to (Norris 2001). Frankly, there seem to be no straightforward connection between new-internet policy reforms in the ICT industry and closing the digital divide (Howard et al. 2009: 1159-1169).

Recall, in the mid-1990s, most of the Internet's computer nodes were physically based in the USA where a handful of other wealthy nations, and most Internet users were at universities, in government and military agencies, or living in urban areas and paying for dial-up services (Davison and Sheila 2003). By the late 1990s, new ICTs were diffusing rapidly, but unevenly, around the world (Howard et al. 2010: 110). According to Howard (2006) and Kling (1996), at this time in history, new Internet users in most countries belonged to specific categories of race and class and were more often creative, well educated, and younger, which had implications for the kinds of civic engagement, social interaction and resources found online (Howard 2006; Kling 1996:297-314). The point is that the benefits of the fast, multimedia networks in today's Internet-driven world economy are accruing disproportionately to those who can afford access or live in countries where usage/access is allowed (Badshah et al. 2005; Mossberger et al. 2003).

Drawing from Emile Durkheim's (1984) functionalist view on inequality, every society operates in a particular order that requires individuals to play certain roles in society. This targeted division of labor provides a greater return for the society and individuals involved, in such a way that this kind of institutional framework is often vulnerable to inequality. In other words, individuals specializing in certain tasks often are rewarded more than the others for their role in the society-on the grounds of a system of incentives constructed by that very society which supposedly should justify inequality (cf. Durkheim 1984, Witte and Mannon 2010).

Drawing from the functionalist view of inequality, it does not matter that many African regions do not use some internet applications, content and services, if, at the end of the day, certain societies and (western) regions, or population benefit from the information and resources provided by those internet vendors. Functionalist theorists would argue in this case that what matters is not whether everyone can access those internet services, but whether the world (although polarised to the West) benefits in general, while ignoring the countless number of others in the global population system (especially from the developing regions) not using those internet services. Therefore, the argument that the inequality attached to this particular division of benefits becomes justified and thus becomes the byproduct of a social order that constitutes the internet economy. Taking from the functionalist position on social order, the overwhelming evidence of internet inequality in this article focuses on how internet applications, contents, and services are accessible from certain locations but restricted for certain 
African regions. In this article, we argue that these kind of restrictions are perhaps a demonstration of a functionalist social structure in the internet ecosystem (cf. Witte and Mannon 2010). Although on a peripheral level, Witte and Mannon (2010) discuss how internet conglomerate Yahoo! focuses on sharing targeted contents that are aligned with the interests and needs of a privileged group of Internet users. This perhaps might also be an example of internet inequality: though open for the public, but targeted towards a particular group of people.

On a more serious note, the internet is designed in a way that guides certain web users to specified channels of resources and network links, in order to function in the order of its functional skeleton. So then, why bother about web inequality since a stream of online users benefit from the set up-hence, inequality is justified! Again, we see this pattern of inequality repeating itself across different web platforms and services. Before its extension of operation, PayPal for example, locked-out users from certain regions in Africa from using their services and focused on providing services to the Western population. Even with PayPal recent penetration in some African countries such as Nigeria, still, some services (e.g., the payment receiving feature) are not yet fully functional for their clients in countries like Nigeria (cf. Nairaland.com 2015). Most of the global South (especially African countries) were not beneficiaries of the PayPal operation even though PayPal was the major source of e-payment at that time. Again, based on the functionalist ideology, they met the needs of certain selected regions and groups, which served their interest (cf. Caprio 2014; Nsehe 2014). Today, there are still countries in the global south that do not have access to the PayPal application.

However, internet inequality is more than a mere functionalist propaganda. It is the lack of sensibility. Van Dijk and Hacker (2003) proposed four different forms of internet inequality, which they contend is a question of "access". In other words, the extent of internet inequality depends on the kind of access defined or denied. The first is the lack of "psychological access", which simply refers to a lack of elementary digital experience caused by a lack of interest, computer fear, and unattractiveness of the new technology. The second is the lack of "material access". This simply indicates a lack of possessing a computer and network connection. The third dimension is the lack of "skill access", which is a lack of digital and professional skills caused by insufficient user-friendliness and inadequate education and social support. The lack of "usage access" signifies the lack of meaningful usage opportunities for the online user, who perhaps has relative experience in the first three categories. (Van Dijk and Hacker 2003:315-326). The fourth type of access is associated with the functionalist view of internet inequality in this article, which implies that access to internet opportunities is given to privileged users and restricted to unprivileged users for the greater good of the internet economy.

Van Dijk and Hacker (2003) further argued that "in terms of material or psychological access to computers and the internet, internet inequality is closing in developed countries, whereas in developing societies it is still growing" (p. 315-326). However, Africa's relationship with the Internet and its governance seem to be improving in the first three categories of internet access, with the exception of usage access. Lack of usage access is therefore argued to be a major challenge for the millennial generation in Africa as they converge online and struggle to use the limited Internet-related resources and services available to them to solve urban and rural challenges within their communities. 
Particularly, the kind of enforced geo-restrictions experienced when there is an interest to access certain websites, web applications (like PayPal, Wordpress, Google checkout), online contents, or host a website but cannot access the online resources or fully utilize its applications because of your geographic location.

The emphasis in this article is to stress why geo-restrictions and regional lockouts over certain internet-related opportunities are problematic for millennials in Africa who are actors in innovation and internet-fuelled development.

\section{Methods}

We have made an attempt to write this article within the confines of a scientific inquiry. As a result, we adhered to some general scientific rules in order to accurately describe the ideas, procedures, and outcomes of our study (cf. Hoogenboom and Manske 2012). However, we may have skipped some formalities and instead, focus more intently on our argument and position to highlight the experiences of Africa's millennial population, who are actively connected to the internet and using it as part of their daily activities, as well as to solve rural and urban challenges in their communities and equally disturbed over their shared marginalization over internet-related services.

It might interest the reader to remember that our approach is the narrative inquiry methodology, also known as the storytelling methodology. This is a method of qualitative research in which the storyteller uses field texts in the form of stories, journal reports, online forum discussions and comments, notes, interviews, photos, conversations, and experiences in general, as the units of analysis to report and interpret the way people create meaning in their life's experiences through narratives (Riessman 1993). Narrative inquiry is a qualitative methodology where the narrative inquirer tries to understand human experiences through recursive, reflexive means-"moving from field (with starting points in telling or living of stories) to field texts (data) to interim and final research texts" (Clandinin and Huber 2010: 124). Hence, the commonality in place scenarios, experiences and situations create a conceptual framework within which the themes emerge and analyses done. At the core of its practice, the narrative inquiry or storytelling methodology is most appropriate for researching ethical matters that have to do with human dignity (cf. Clandinin and Huber 2010; Musimbi 2002). This is why we employed this methodological approach in telling the stories of a marginalised social generation in order to construct a theoretical understanding around the experiences of Africa's millennial generation in the internet ecosystem.

We took the storytelling approach and gathered reports, comments, forum discussions, and notes from various known and unknown young entrepreneurs and innovators within Africa who are a larger part of the Third Millennium Africa Project (TMAFRICA) ecosystem; most of whom are based in Africa and innovators in their own right, and equally between the millennial age brackets (1982-2001). Some of the stories were gathered during the "Spotlight Talks" interviews (a monthly initiative of TMAFRICA) with promising African millennial leaders who are solving rural and urban challenges using the Internet technology. Most of them were asked the challenges they were facing in their work. Their answers have helped us to put together this narrative. Others were taken from random online comments, forums, and notes recovered from African millennials who were frustrated with online platforms that were making them victims of their functionalist internet social structure, which seems to 
satisfy the online "usage access" needs of certain "privileged" regions, and thus leaving out the collective "usage access" needs of other regions who, as a policy, are not allowed to have full usage access to opportunities and resources in some online platforms. Equally, relevant literatures and evidences were used to support and backup these claims as well.

\section{Results: Internet geo-restrictions and regional lockouts as constructed forms of internet inequality-telling the stories of African millennials} The "connected" and "innovative" African millennial generation

According to Ball-Rokeach (2001), the term "connected" reflects a multi-level and contextual way of envisioning the relationship between individuals and technology (cf. Ball-Rokeach 2001:485-510). Being technologically connected in a general sense suggests an increased internet penetration and demand. Of late, Africa's internet penetration has been at an all-time high-with an estimated growth of $27.0 \%$ with 313,257,074 users as of June 30, 2015 (Internet World Stats 2015). Consultants at the McKinsey Global Institute have equally estimated a double penetration of $50 \%$ by 2025 with an influx of over 360 million smartphones on the continent (cf. Manyika et al. 2013). With the increased connectivity to the internet among millions of unemployed and innovative tech-savvy millennials across the African continent, it seems that internet connectivity is bringing tremendous opportunities and revolutionizing home-grown solutions in Africa, as Africa's millennial generation boost their own prospects using the internet technology to transform businesses, and drive entrepreneurship and economic growth (cf. World Bank 2012; Kalan 2013; Dutta et al. 2015).

Today, over 313 million people living in Africa regularly use the Internet (cf. Internet World Stats 2015). The World Bank funded report, eTransform Africa, provides data on the ICT revolution that is taking place in Africa and its transformational prospects on the continent's development as of 2012.

At the start of 2012, there were some 650 million mobile subscriptions, making the African mobile telephone market bigger than either the EU or the United States. Some $68,000 \mathrm{~km}$ of submarine cable and over $615,000 \mathrm{~km}$ of national backbone networks have been laid, greatly increasing connectivity across Africa. The Internet bandwidth available to Africa's one billion citizens has grown 20-fold since 2008 (World Bank 2012).

In a more recent 2015 United Nations Economic and Social Council report on "Digital Development" by the Commission on Science and Technology for Development, it was estimated that mobile broadband and smartphones will be the key driving force of future technology trends in ICTs. With over 200 million millennials between 15 and 24 in Africa, the majority of future technology pioneers would come from Africa's millennial generation, given that they are the largest population of young people in the world (cf. Ighobor 2013).

Today, a growing number of millennials in Africa are actors in innovation due to internet connectivity. With the growth of internet penetration and connectivity, there are positive stories of Africa's millennials contributing to internet development through their internet-inspired innovation. Looking across the web, there are hundreds of inspiring success stories from Africa, as we will share just a few. 
The story of Chike Maduegbunam, a businessman from Nigeria, and the creator of the popular Afrinolly mobile app, which has almost a million downloads is a good example. With the passion to bring Nigeria's entertainment industry to the world, Chike's team developed Afrinolly for this purpose; therefore making it easy for anybody from any part of the world to have access to Nollywood movies through their smartphones.

Another inspiring example is the Funda e-learning platform, a South African-based online learning solution. Funda is argued to have one of the best e-learning platforms created specifically for developing countries. The funda platform has made it possible to "integrate already existing solutions at Universities to take courses online”, says Kola Olajide, the Cofounder and lead engineer at funda during his Spotlight Talks interview with TMAFRICA. Funda is an exceptional e-learning platform because of its user experience that takes account the delivery mechanism, data analysis, and assessments for learners. They currently provide e-learning solutions to Universities in Southern Africa, and gradually dominating the rest of Africa. According to Kola Olajide (2014), "funda works with educators to make sure the content is digitally ready and prides itself in providing a complete solution to the education ecosystem." The funda technology is so innovative that companies in Europe and America are interested in partnering with their platform, according to Olajide.

Amr Sobhy is another African millennial success story from Egypt, whose technological exceptionalism has propelled change and civic engagement within and across Egypt. After the Arab Spring crisis that led to the removal of the then Egyptian President Mubarak, Amr designed an internet application known as MorsiMeter to monitor the progress and promise of the then new Egyptian President Morsi within his first 100 days in office. For Amr, his connectivity to the internet has allowed him to use the Internet technology to empower people and bring about some sort of civic engagement (cf. Sobhy 2014). Amr hopes to use technology "to practice democracy in a way that is beyond the ballot box".

Seeing himself as an information activist, Amr had equally used technology to solve other problems that really interest him. In his Spotlight Talks interview with TMAFRICA, Amr admits that he had started other innovative internet projects which according to him are like the different hats that he wears. With his undergraduate background in Pharmaceutical Science, Amr equally developed Dawaa-an online drug index that makes it easy to answer questions related to drug names, doses, brands, and prices. Amr notes,

"I was actually surprised that...in 2014 that the only way to navigate that [drugs names] is through a book and some list of apps that are really out-dated. And that's because lately it's a niche problem and no one is interested in solving it. It's a lot of money, and there aren't really that many pharmacists out here. It was a really interesting problem for me and I created Dawaa as a weekend project. I created the first digital drug index with a very simple to use interface and it also adds a lot of enhancements to the functionality: like if you want to search by the name and the brand and figure out some information about them, and which is the cheapest and the most expensive. This is something that was not even possible using books."

Amr is also the creator of PushBots and Zabatek, online tools he developed for not just the Egyptian population but for the world at large. 
Other inspiring examples include the Egyptian Nihal Fares who is the co-founder of Eventtus, a social networking app that enables its users to find social events and networking opportunities matching their interests; Tebogo Mogale and Sammy Rabolele's Beyond The Eyes online TV, which is the first black-owned online TV to come out of South Africa; and Alan Knott-Craig, CEO and founder of Project Isizwe, a start-up bringing free Wi-Fi to South Africans-connecting people for online education opportunities, economic development and social inclusion (cf. TMAFRICA Spotlight Talks, 2014-2015).

Without doubt, access to the Internet and mobile phones are transforming the development landscape in Africa, injecting new innovative opportunities and information in key sectors (Saghir 2013). And more so, creating new actors and change makers of transformative and innovative developments from Africa. Indeed, internet-related developments have empowered millennials in Africa to drive entrepreneurship, innovation and income growth in Africa (Yonazi et al. 2013).

\section{The "constrained" but "innovative" African millennial generation}

As we move further, it is important to reiterate the type of internet inequality we are looking at: the lack of usage access/opportunities (Van Dijk and Hacker 2003). The lack of significant usage access to opportunities is the kind of internet inequality, watered by a functionalist worldview, where certain internet services, resources, and intellectual property are restricted to benefit certain privileged online users in the internet ecosystem. Such kind of internet inequality, according to Van Dijk and Hacker (2003), demonstrate that 'free' internet access or computer hardware is not really free, of course. There are nominal monthly fees, long-term service agreements, privacy selling and low-quality service, for instance." (p. 11). Van Dijk and Hacker (2003) further described the reason for this inequality: "It is simply a question of some having the technology now and others having it later. They first pay for the innovation and make later adoption cheaper for the last." (p.11). The idea of usage access generally points to the various uses of internet applications, which include both the active and creative use of the internet technology. Ghobadi and Ghobadi (2015): 332 list examples of this kind of usage opportunities to include but are not limited to publishing a personal website, creating a weblog, posting a contribution on an online bulletin board, newsgroup or community, and website payment integration. The authors further explained that usage access is "largely linked to demographic characteristics of users and connections (e.g., social class, education, age, gender, and ethnicity, effectiveness of the connection)" (Ghobadi and Ghobadi 2015: 332).

We argue that even though Africa's millennial generation are connected to the Internet through other means (e.g., psychological access, material access, and skill access, cf. Van Dijk and Hacker 2003), they are yet to realise the full potential of the Internet technology due to the lack of significant usage access to online opportunities.

As we interviewed certain individuals and observed the trends of internet inequality across the continent, two main recursive experiences (acceptability or identity problem and accessibility or participation problem) are salient among millennials in Africa as they engage the online community to participate as actors in innovation. "Acceptability or identity problem" is an undeniably increasing psychological challenge in internet usage access where certain individuals are not accepted in some online communities 
on the basis of their social or regional identity. On the other hand, "accessibility or participation problem" highlights the salient culture of denying certain individuals the basic human right to participate in some online communities due to certain stereotypical thoughts or beliefs about their identity. We saw these two instances of internet inequality often overlapping with each other, and at some point giving rise to each other. To note, we do not wish to discuss these two forms of internet inequality trends separately, since often times they go hand-in-hand with each other.

Before we continue with the stories, let us first begin with a personal experience one of the authors had in 2013 while living in Nigeria, which actually inspired this paper. Victor is a trained web designer, even though he does not design websites professionally as his main source of income. A friend had asked Victor to assist in providing a web presence for their 5 Star Hotelas they plan on upgrading their services. Victor agreed to help the friend design the website. Victor paid for the web hosting at HostGastor.com using his Guaranty Trust Bank debit card, which he also often use to make online payments from Nigeria. The payment went through successfully. However, the domain was not registered by HostGastor. A complaint was sent to HostGator by Victor using his twitter account on February 14, 2013 (see image below), and HostGastor responded saying, "The domain appears to be currently available as it wasn't registered due to the lack of follow through on the verification". The "follow through on the verification" (see screenshot of email below) they were referring to was to send a photo picture of the debit card Victor used for the payment, with a photo of him holding the bank card, and a copy of his International passport or ID-which he did. After waiting for almost a week to approve the domain hosting, HostGastor still delayed on verifying the transaction. The truth was, as one of the HostGator staff told Victor in an honest disclosure, that the company does not accept users from his geographical location on their platform due to fears of Internet fraud since there was a general notion that everyone using the Internet from West Africa was either a fraudster or involved in some kind of identity theft online. On knowing the truth, Victor had to cancel the transaction since it was almost about 2 weeks since the initial payment. It took Victor another 2 weeks to receive a refund.

While trying to bring about innovation in the hospitality business by giving it a web presence, Victor was denied access to host a website on a hosting platform that only serves a specific geographical region. Once again, we see how the functionalist position

HostGator - Verification Requested
verify@hostgator.com
to me
Thello,
In order for us to continue with the account setup, please respond to this ticket with a scanned copy of a Photo ID such as
as a passport, or drivers license. In addition to a photo ID, please include a scanned copy of the credit card that was used
in your account purchase (assuming you purchased a hosting account with a credit card). For security purposes you can
mask off all the digits of the card number except for the last 4 digits.
We sincerely appreciate your cooperation here, and look forward to working with you.
Thank you,
HostGator.com Sales Team
Customer ID: 1613028




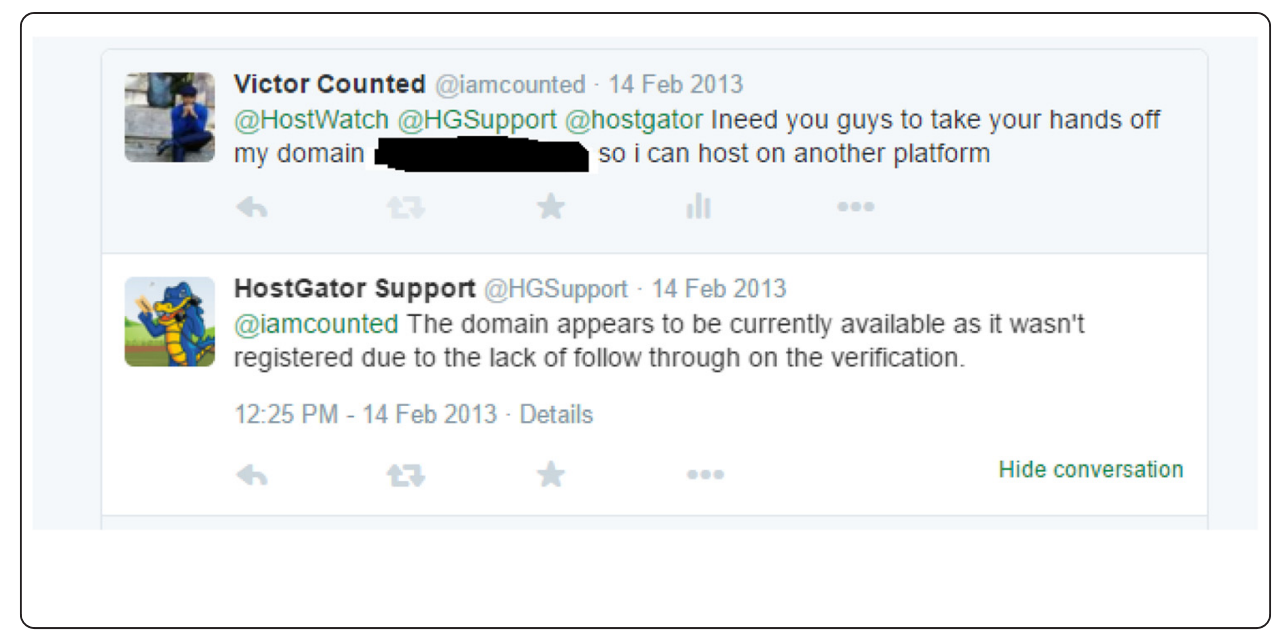

of internet inequality is structurally formalized in the internet ecosystem, serving only a specific group of users.

Although there are other hosting platforms that are willing to accept payments from Victor's geographical location, a major challenge for innovation among millennials in Africa, as we observed, is having a universally recognized e-payment integration system.

Following an ordeal with PayPal.com, user "Normaljenny" in an online forum discussion on nairaland.com (2012) was seeking advice on how to advance his online business which would require an e-payment processor to complete his new online project. His fears was that while he might be able to create e-payment processors using payza and checkout (which are e-payment systems designed for users from developing countries) the problem was that it would be preferable to use PayPal, since, according to him, "is just too trusted and accepted worldwide". User Normaljenny has a fiancée in the USA and contemplated asking her to use her Social Security Number to open a new bank account for him so that he could use the details to verify his PayPal account in order to integrate PayPal's e-payment processor into his new business website. Normaljenny equally considered going to a neighboring country like Benin Republic since PayPal was not operating in Nigeria at this time, but available in Benin. Normaljenny is now receiving feedback and recommendations on what to do by fellow forum users. Most of the responders also shared their own PayPal experiences-most of which had very similar storylines. Not to mention Google Checkout, which Normaljenny claimed to have tried, but was locked out and unable to access. In her/his words, "I tried Google checkout and they have only USA and UK as allies and you must verify with credit card "made" in USA or UK, or your tax this and that."

User Normaljenny complaints on nairaland.com are here captured on the screenshot below.

In particular, while other forum responders shared their own experiences and recommended change of VPN/IP to USA dedicated IP, user "Marvid" in particular does not subscribe to the idea of changing an IP address. Marvid clarifies the situation on the 


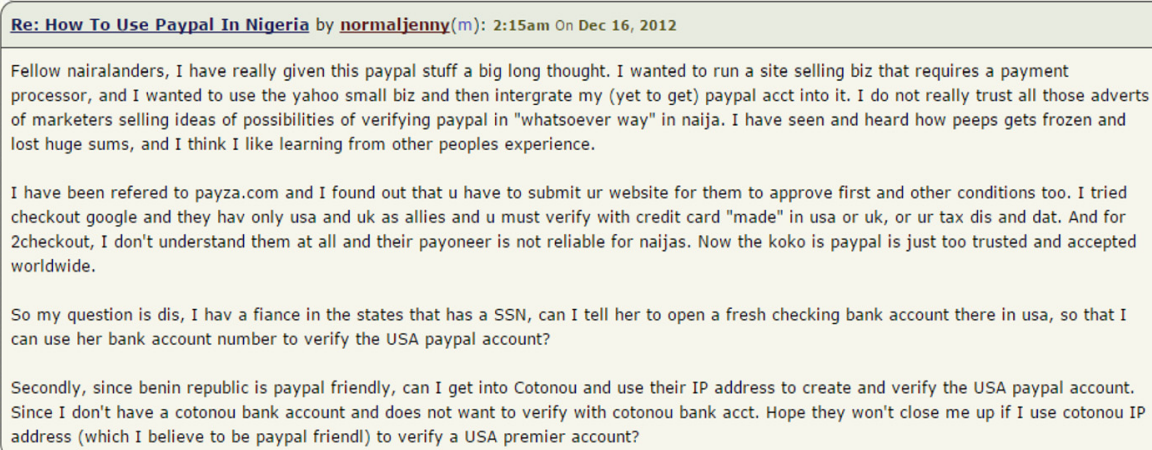

forum challenging other forum users with a question: "If you a Briton and you are living in Nigeria, does that mean you cannot operate your paypal?" Marvid insists that it is not about their IP address but their nationality. See Marvid comments in the screenshot below.

Paypal's e-payment integration in Marvid's website seems not to work properly, as seen in the screenshot captured below, showing PayPal's default checkout response ("This recipient is currently unable to receive money"), which means it is impossible to

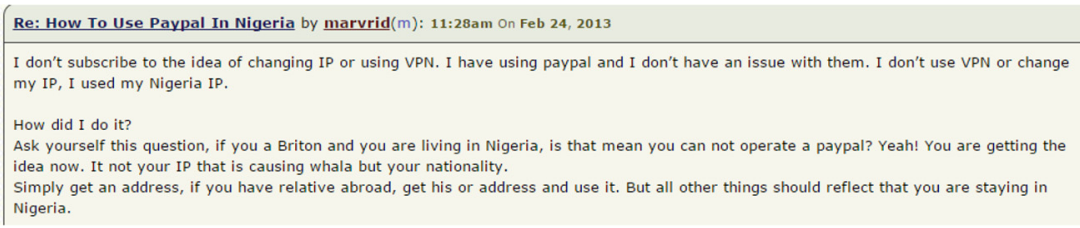

make a purchase on Marvid's website. An attempt to open Marvid's business website (www.marvrid.com) shows that the site is no longer in service; perhaps due to the restriction not to receive payment due to his location. Of what benefit is it to sustain and maintain an online service or business you cannot even receive payment for? PayPal's refusal to allow Marvid to integrate their e-payment system into his website and thus receive online payments for his business is captured in the screenshot below, as attempt was made to test-run his PayPal payment system by one of the forum users prior to the final shutdown of his online business on marvrid.com.

On the other hand, user "legalwealth" captured the situation of "usage access" in Nigeria with emphasis to PayPal as of 2013 in the screenshot below.

However, PayPal has recently extended their service to Nigeria in 2014 (cf. Nsehe 2014). And within the space of 1 year, the Nigerian PayPal market became the second largest market for PayPal in Africa (cf. Chima 2015; Ventures Africa 2015). Sadly, even with the acclaimed extension, there are still restrictions as to how Nigerian users should use the PayPal payment system. 


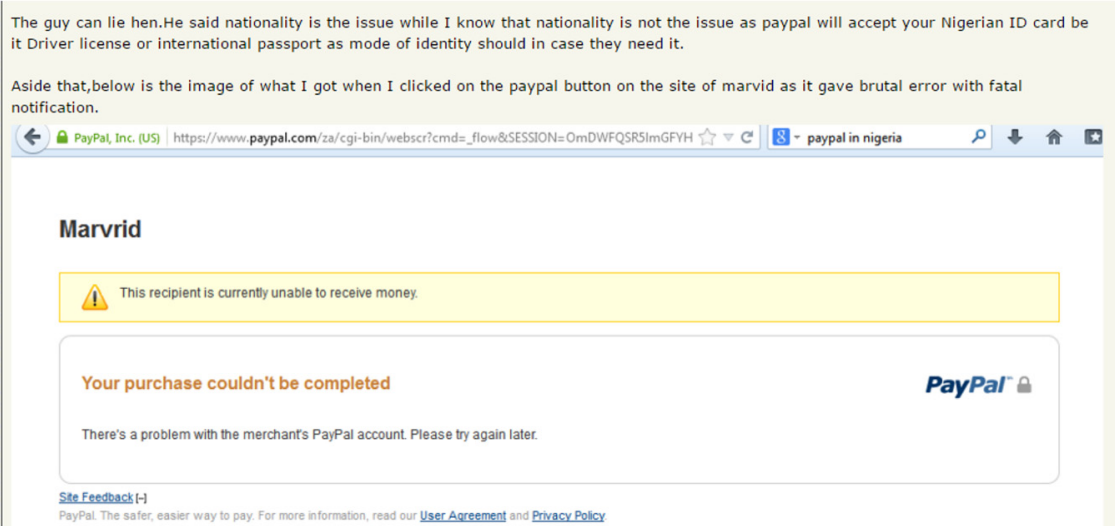

One of the Nigerian users claimed to have sold some of his products online through the new PayPal system introduced in the country but unfortunately could not receive his money because PayPal is of the position that Nigerian users should not be allowed to receive online payments, even though they can use their PayPal accounts to make payments to other PayPal users. Miskoblog.com notes this in their article as below:

A Nigerian PayPal account can only be used to shop online on merchant sites that accept Nigerians and also to send money to accounts eligible to receive PayPal payments. For example you cannot send money to another Nigerian PayPal account but you can send to a USA PayPal account which is eligible for receiving payments on PayPal (Miskoblog 2014: para. 5).

Compare this claim with the screenshot below (cf. Nairaland.com 2015), as one of the forum users asks how he/she could withdraw money from his/her PayPal account and user "BuddahaPalm" clarifies saying, "Nope...Y You can't receive. Potential sender gets a message telling him that as well".

To put forward, some of the millennials in Nigeria are aware that PayPal has extended their services to the region but other third party PayPal accredited web vendors like 


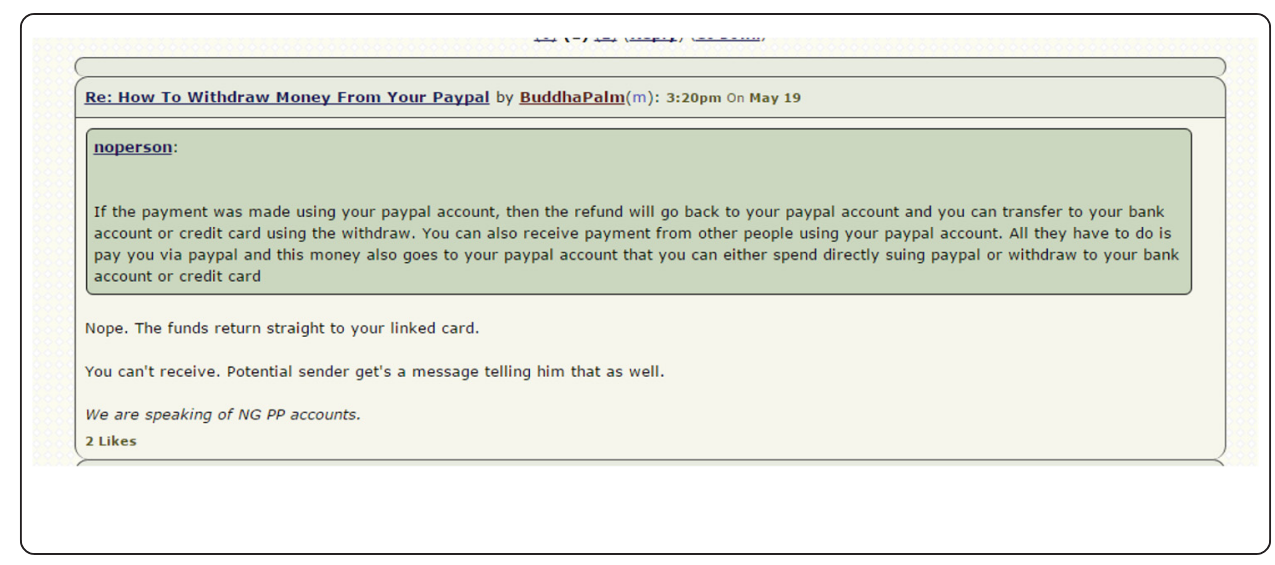

Wordpress seem not to have upgraded their system to include "Nigeria" in their checkout database. Timothy Ozovehe (2014) complains in his comment on a Wordpress forum, frustrated trying to pay for a wordpress service but unable to do so since Wordpress, according to him, seems to have a "personal issue with Nigerians". This is captured in the screenshot below:

Overall, one of the common trend in the discussion forums is seeing many of the online forum users, who at some point serve as advisors, rationalizing that their experiences with PayPal were the springboard that inspired them to create and support new African-initiated e-payment alternatives (e.g., GTBank GTPay, Interswitch InternetPay, eTransact, Simplepay,

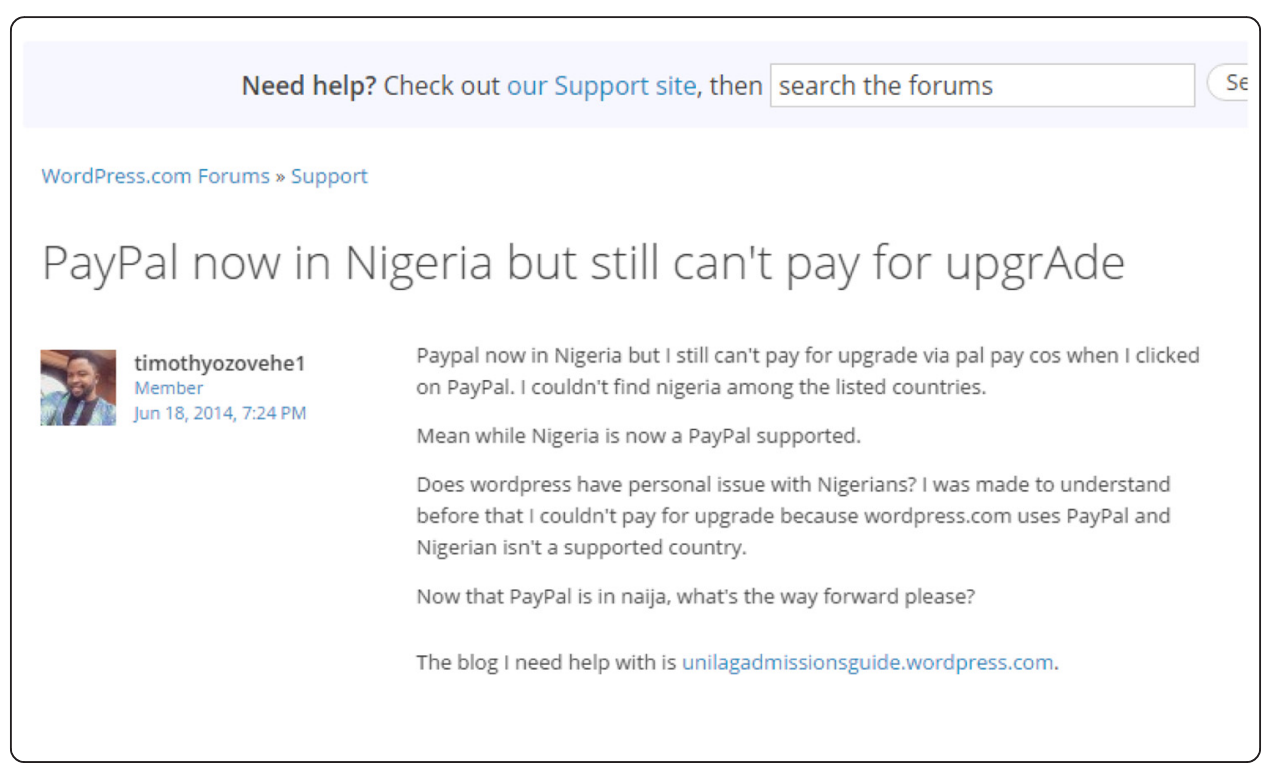

Cashenvoy, UBA UCollect, Zenith Bank GlobalPay, 2Checkout (2CO), Payza, and Paga) designed specifically for the African market (cf. King 2015). Many of the founders of these new e-payment systems draw their inspiration for starting their own e-paymentcompanies based on the difficulties surrounding online payments in some parts of Africa. African millennial, Simeon Ononubi, founded Simplepay in 2013 after his frustration with Westernbased online payment systems like PayPal that do not understand the African market and often think of African e-payment users from the lens of negatives stereotypes. According to Ononubi, in his interview with Muyiwa Matuluko of Techpoint Nigeria, he has this to say, 
"I don't believe that you can just borrow something from America and use it in this environment." (cf. Matuluko 2015: para. 1). With Ononubi's Simplepay, African users can securely and conveniently make online payments simply by using their email address and bank account as a "sort of reminiscent of PayPal", Matuluko (2015) claims. Today, Simplepay has over 10,000 registered users monthly (cf. Matuluko 2015) and the company continues to grow as it hopes to reach one million users by the end of 2015 through a grand partnership with the African banking giant, Zenith Bank PLC (cf. Matuluko 2015).

Simplepay seems to excel in a difficult African e-payment market terrain. However, PayPal still wields the upper hand since the PayPal system is universally recognised and respected as a more secure and reliable e-payment system due to its popularity. For millennials who are in desperate need of the PayPal payment system, using the Simplepay e-payment system is just not an option, especially when their client base is in Europe and North America.

Occasionally, we noticed some of the desperate forum users in need of the PayPal system, resort to manipulating their identities in order to gain access to PayPal and sell their products to the Western market, where PayPal is the most trusted means for online payments. We see this in the screenshot below, as forum user "Arewatch" on nairaland.com now beckons on "wanna-be" PayPal users, who are willing to take any risk to get verified PayPal accounts for their online businesses (cf. Nairaland.com 2013).

As we move our attention away from the narratives that support the subtle existence of internet inequality in the internet economy, we now focus our attention back on the stories of millennials who are part of the Third Millennium Africa Project ecosystem and their comments on internet inequality from a broader spectrum. These comments and observations were gathered during the recent Spotlight Talks interviews they had

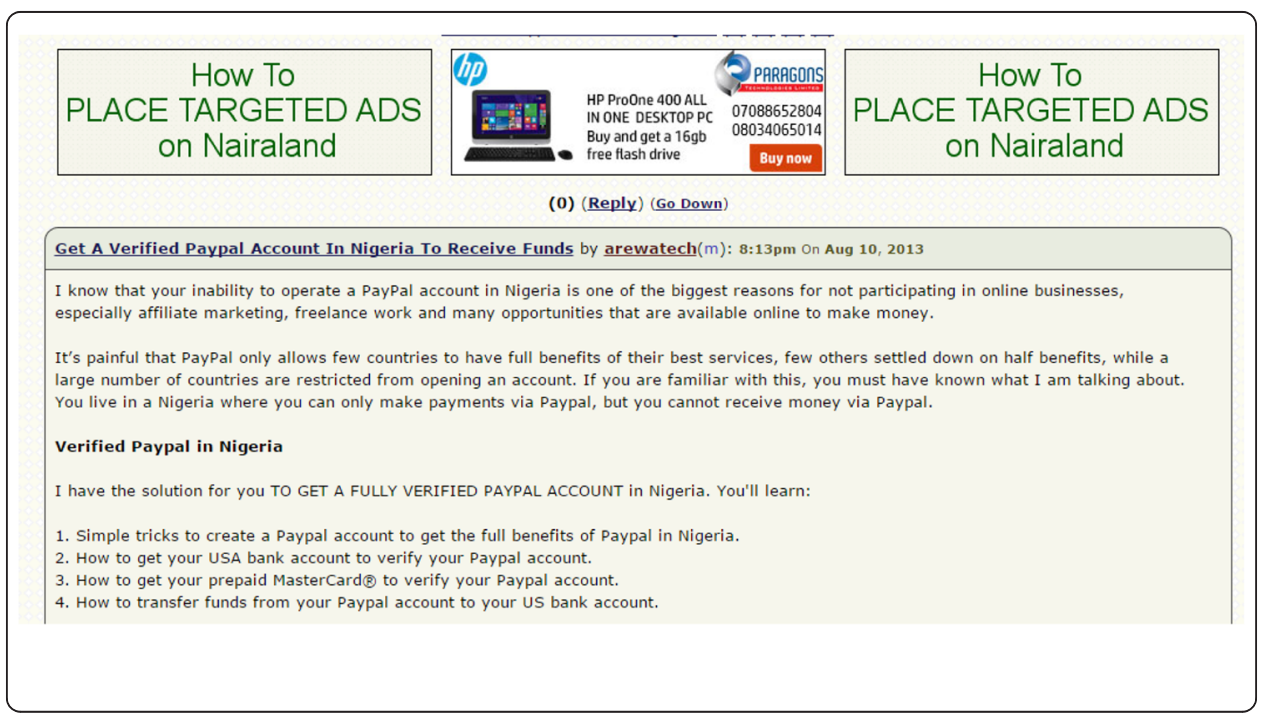

with TMAFRICA, when they were asked to talk about their start-up projects and the challenges they were facing in their different fields.

Kola Olajida, the lead engineer at Funda (an emerging e-learning system) who is originally from Nigeria, in his Spotlight Talks interview (cf. Olajide cited in TMAFRICA 
2014), notes how difficult it was for him to start his niche in Nigeria due to the negative stereotype associated with that particular region. He believes that South Africa was a better playing ground for his e-learning project launch, which has recorded some incredible success over the years. But what if Kola could not afford the means to relocate to Cape Town; what could have been of his Funda dream?

Kola is not the only one of our ambassadors who seems to have been a victim to internet inequality. Internet information activist, Amr Sobhy (2014: para.7), equally shares the same concern as he intellectually captures the trend of internet inequality in his Spotlight Talks interview with TMAFRICA:

"When it comes to the entrepreneurial scene in Africa, there are a lot of challenges... the basic challenge is the ecosystem is not as well or as mature as in other continents and in other countries. And sometimes there is actually a huge gap between what we have here as a reality and what exists in other places. It is ok because we need to start somewhere."

Indeed, the problem with internet inequality is in the internet ecosystem, which is configured to benefit certain regions whereas giving "internet milk" to "internet babies" in other regions. The internet usage access gap between what is obtainable in the internet economy from African countries is far below what is the standard in other places. Amr believes that the internet stakeholders do not see the value in investing in the African market but "They are willing to spend the same amount of money but in more experienced places as investors. Like they don't want to invest locally, but they are willing to invest 2 to 4 times that money, but in other more mature ecosystems which will not help African entrepreneurs and startups to really grow." However, we don't have much of a choice, and like Amr states, Africa "need to start somewhere" (Sobhy cited in TMAFRICA 2014: para.7).

We believe there is an awareness "out there" about what internet inequality is all about, which often points to the deep-seated understanding (or misunderstanding) of internetgenerated inequality and online interaction. In fact, building engaging interfaces online can be a daunting task that does not go without encountering some form of inequality or stereotype, especially when surfing from the breadth of Africa.

To put it more clearly, Piragoff (2005) reasons that the way in which virtual communities are organized into predictable relationships, patterns of social interaction (the way in which people respond to each other) are to some extent a precursor to cybercrime (Piragoff 2005:133), and for us, an evidence of the injustice of inequality roaming the internet ecosystem. When access is denied based on one's identity or a perceived stereotype, a more acceptable but vague identity is often forged to gain access and acceptance as we have seen in the narratives. At the end of the day, nobody actually wins. And this, for us, is the more reason why identity theft is more rampant in the internet economy. Unfortunately, usage access to opportunities and resources on the internet still remains an unbelievable reality and a major challenge facing the future of Africa's millennial generation.

\section{Discussions: A case for internet equality and full usage access to internet opportunities}

Throughout the developing world, creating access to sophisticated services for the most marginalized populations is a huge challenge (cf. Dalberg 2013). Those who are 
connected online can testify that the Internet is a tool with great potential. Yet, the expansion of the internet is a contradictory phenomenon. There is significant evidence of inequality in Internet usage access, especially in terms of "proprietary production models and intellectual property rights" (United Nations Economic and Social Council, 2015: 11). While there are forms of online activities and policies that encourage Internet penetration in Africa, there are some Internet models, protocols, and intellectual properties that are restricted or locked out for some African countries. As a result, millennials within these regions miss out on a great deal of online resources and opportunities on these platforms.

The internet introduces huge social inequalities due to its functionalist downside. The distribution of users is polarised due to economic and social status and inadequate economic structures in many parts of the world (Conachy 1999). The 2015 United Nations Economic and Social Council report links this inequality to the lack of open source models like the open source software production which are based on a commitment to share and open participation to online community users without any enforced geographical restriction that serves a particular region. Looker and Thiessen (2003) are of the opinion that geographical location has an impact on patterns of use and attitudes to new technologies. The authors argue that internet inequality will be a persistent phenomenon that is likely to "affect the ways and the extent to which members of different subgroups involve themselves in the information society" (Looker and Thiessen 2003:487).

Though an incredible, undisputed force for unleashing new forms of connectivity and opportunities, the Internet ecosystem needs some critical reforms. Breaking the barriers that are necessary for achieving a competitive advantage in the internet economy is essential for Africa's growth in order to connect Africa's millennial generation to opportunities on the internet that will enable them to create innovative solutions for rural and urban challenges in Africa. Not only will an improved reform on usage access impact Africa's millennial generation, it equally would provide an outlet for new forms of innovation, entrepreneurship, and social good. As a result of an improved access to Internet opportunities in developing countries as of 2009, according to the World Bank report, there has been a $10 \%$ increase in broadband which correlates to a $1.38 \%$ increase in GDP growth (Qiang 2009). Imagine what would happen if the negative stereotypes about Africa were laid to rest?

As for us, we envision Africa where innovation and development are commonplace through access to the right information and resources. It would be a daunting vision if Africa's future generation are denied the human right to access opportunities and resources in the Internet economy like their western counterparts.

In Dalberg's research, survey results of over 1300 firms in Africa cited access to information as one of the Internet's most significant benefits for their businesses-but agricultural firms voiced the strongest emphasis with over $70 \%$ of respondents ranking access to information as "essential" (Dalberg 2013). Access to solutions in agriculture are demonstrating impact on operations, leading to direct impact on household incomes. SMEs within the agricultural sector have used a range of new tools, such as Nokia Life Agriculture Services and Ghana's Esoko, to obtain information that was once difficult to find over long distances, such as market prices and weather information (Dalberg 2013). 
Yet, PayPal, Google Checkout, wordpress, HostGator, and the likes still have not fully recognised several African countries in their e-payment network. And not to forget, several cases of IP address restrictions to many websites have been of great concern to internet inequality as well. While all these seem to be the consequence of an ongoing battle to mitigate cybercrime, this approach seems to overall be self-defeating and limits access to information and opportunities that may as well help young people in Africa, within these restricted confines, to succeed and live above the poverty line. What a shame!

Apparently, one of the important lessons of the past two decades has been the central role of innovation especially in the area of the Internet technology in economic development (Organization for Economic Co-orporation and Development OECD 2005). A challenge, however, is to ensure that innovation and channels through which innovation can take place are inclusive; that is, to ensure that the benefits are shared more evenly across all groups and regions in order to improve the overall social wellbeing of mankind, because we are all human beings!

Good governance of the Internet economy and its related technologies is necessary for progress on economic, social, and environmental levels as we progress into the future. Creating a fair atmosphere that allows millennials in Africa to freely and fully connect to the rest of the world online is important. With unlimited access to the Internet economy, millennials in Africa not only have access to online information and opportunities, but can become actors in innovation as they transform from morally decentralized to digitally transformed role models in their communities. By granting them full usage access online and deconstructing the functionalist structures of internet inequality, the hope of rebranding the African image can come alive and strong as young people share stories of Africa's growth, strength, and transformation. Fighting internet inequality is a great way to create social inclusion and access to opportunities on the Internet economy. Opportunities, we believe, that will enhance development and build the capacity to promote ongoing sustainability that will elevate Africa from the abyss of under-development to the playing field of global competitiveness.

Despite Africa's history of bad reputation (Howard et al. 2010:110), concrete efforts must be put in place by policy makers and government organizations as we design ICTrelated policies that will promote a smooth transition to the Internet age for the sake of the future emerging generation of Africans. This cohort of young people are arguably the largest in the world (cf. Ighobor 2013), and are unique from the previous generation because of their technological exceptionalism (cf. Howe and Strauss 1991, 1997). Such internet policies must include but not remain limited to providing full Internet usage access to our promising future African leaders. Other areas of access should be explored as well.

In order to accomplish this, however, there must be grassroot reform that links the relationship between economic corruption and the freedom to access meaningful information and spread ideas online. Regardless, adapting the internet into our society to fit and wrestle our morally challenging borders requires not just an overflow of cultural and contextual relevant opportunities but an inclusive internationalization of Internet governance-inclusive of all nations, and not regulated on geographical, racial, sexual, or individual basis-to assure a complete internet breakthrough in Africa.

On humanitarian ground, internet vendors need to operate an open internet policy for the sake of human dignity, in order to empower the edges (where Africans seem to 
settle) of the Internet economy rather than the center. With such kind of user-centric template, voices are given to even the end-users and everyone benefit at the end of the day (Seidler 2013).

\section{Conclusions}

While we took note that access to the Internet in general has largely contributed to Africa's advancement, we equally contested that the challenge for a huge percentage of Africa's millennials is the lack of meaningful usage access to opportunities and resources on the Internet, specifically created for users in the global North and countries in the West. We argued that this kind of internet structure represents the functionalist view of internet inequality, which fundamentally is created to benefit a particular social group in a social system. Using the narrative inquiry, we narrated stories of how millennials in Africa are sidelined on the margins of the Internet ecosystem as part of the functionalist agenda to apportion a large portion of opportunities available online to users from Western countries. Hence, citing how PayPal, Wordpress, Google check, HostGator, and other internet vendors are agents of internet inequality, carrying out this functionalist agenda within the Internet ecosystem.

Drawing from these stories, we contend for a full usage access to meaningful internet opportunities, which is the primary area of internet inequality experienced by millennials in Africa who are skilled with the knowledge of the internet technology. The human right to access information or resources or utilize an application online should not be determined by an "insensitive few" who enforce geographical restrictions on the most useful Internet products on the basis of a functionalist propaganda and stereotype.

Needless to say, Africa's ongoing internet-fuelled developments lie in the creative hands of Africa's millennials as they exchange ideas and engage the rest of the world online without undue restrictions to participate in online communities, contribute to the internet technology, add to the positive stories about Africa, and benefit from the bottomless opportunities that abound in the internet ecosystem.

Competing interests

All authors declare that they have no competing interests.

Authors' contributions

All authors read and approved the final manuscript.

Received: 10 April 2015 Accepted: 24 November 2015

Published online: 16 January 2016

References

Badshah, A., et al. (2005). Connected for development: information kiosks and sustainability. New York: United Nations.

Ball-Rokeach, S. J. (2001). The origins of individual media system dependency: a sociological framework. In Communication research journal. Washington: Washington State University.

Bell, H., \& Tang, N. K. H. (1998). The effectiveness of commercial internet websites: a user's perspective. Internet Research: Electronic Networking Applications and Policy, 8(3), 219-228.

Bolsover, G., Dutton, W. H., Law, G., \& Dutta, A. (2014). "China and the US [United States of America] in the new Internet world: a comparative perspective, in society and the Internet.". In M. Graham \& W. H. Dutton (Eds.), How networks of information and communication are changing our lives (pp. 117-134). Oxford: Oxford University Press.

Caprio, D. (2014). Bring Paypal to Nigeria: Nigerians petition PayPal. Accessed online 23-10-2015 at http://geek.ng/2014/ 06/bring-paypal-nigeria-nigerians-petition-paypal.html.

Chima, O. (2015). In less than a year, Nigeria now Paypal's number two market in Africa. Accessed online 27-10-2015 http://www.thisdaylive.com/articles/in-less-than-a-year-nigeria-now-paypal-s-number-two-market-in-africa/203834/.

Clandinin, D. J., \& Huber, J. (2010). Narrative inquiry. In B. McGaw, E. Baker, \& P. P. Peterson (Eds.), International encyclopedia of education (3rd ed.). New York: Elsevier.

Conachy, M. (1999). Social inequality and the World Wide Web. Accessed 19/10/2013 at https://www.wsws.org/en/ articles/1999/08/www-a17.html. 
Counted, A.V. (2016b in press). 'Being Authentic is the New Image: A study of authenticity and selfhood among south african christian millennials'. Mental Health, Religion \& Culture.

Dalberg. (2013). Impact of the internet in Africa: establishing conditions for success and catalysing inclusive growth in Ghana, Kenya, Nigeria and Senegal. Accessed online 10/22/2013 athttp://www.impactoftheinternet.com/pdf/ Dalberg_Impact_of_Internet_Africa_Full_Report_April2013_vENG_Final

Davison, E, Sheila, C. (2003). Connection discrepancies: unmaking further layers of the digital divide. First Monday. Accessed online 10/05/2013 at http://firstmonday.org/htbin/cgiwrap/bin/ojs/index.php/fm/article/view/1039/96

Dholakia, N., Dholakia, R. R., \& Kshetri, N. (2003). "Internet Diffusion". In H. Bidgoli (Ed.), The Internet Encyclopedia. New York: Wiley.

DOTForce. (2001). Digital opportunities for All. DOTForce.

Durkheim, E. (1984). The division of labour in society. London: Macmillan.

Dutta, S., Geiger, T., \& Lanvin, B. (2015). The Global Information Technology Report 2015: ICTs for Inclusive Growth. Geneva: World Economic Forum.

Everett, C. (2014, November 27). Out of Africa - building on the hub of tech investment. Accessed online 27/10/2015 http://www.diginomica.com/2014/11/27/africa-building-hub-tech-investment/\#.VmibvkrRKko

Ghobadi, S., \& Ghobadi, Z. (2015). How access gaps interact and shape digital divide: a cognitive investigation. Behaviour \& Information Technology, 34, 4,330-340. doi:10.1080/0144929X.2013.833650.

Gillwald, A. (2008). Communication infrastructure. International Encyclopedia of Communication.

Google Africa. (2013). Africa connected: tell us your web success story. Accessed online 10/22/2013 at google-africa. blogspot.com/2013/08/africa-connected-tell-us-your-web.html

Heaven, C., \& Turriby, M. (2003). Highly affected, rarely considered: global youth culture and youth identity. Oxfam Community Aid Abroad: In The international youth Parliament's commission report on the impacts of globalisation on young people. Australia.

Hoogenboom, B. J., \& Manske, R. C. (2012). How to Write a Scientific Article. Int J Sports Phys Ther, 7(5), 512-517.

Horovitz, B. (2012). After Gen X, Millennials, what should next generation be? USA Today. Accessed 09/02/ 2013 http:// usatoday30.usatoday.com/money/advertising/story/2012-05-03/naming-the-next-generation/54737518/1

Howard, P. N. (2006). New media campaigns and the managed citizen. New York: Cambridge University Press.

Howard, P. N., et al. (2009). Sizing up information societies - towards a better metric for the cultures of ICT adoption. The Information Society, 25(3), 208-219.

Howard, P. N., et al. (2010). Comparing digital divides: internet access and social inequality in Canada and the United States. Canadian Journal of Communication, 35, 109-128. Washington.

Howe, N., \& Strauss, W. (1991). Generations: the history of America's future, 1584 to 2069. New York: William Morrow \& Company. ISBN 978-0-688-11912-6.

Howe, N., \& Strauss, W. (1997). The fourth turning: what the cycles of history tell us about America's next rendezvous with destiny. New York: Broadway Books. ISBN 978-0-7679-0046-1.

Ighobor, K. (2013). Africa's youth: a "ticking time bomb" or an opportunity?'. United Nations Africa Renewal: In Africa renewal. Geneva.

Internet World Stats. (2015). Internet usage statistics for Africa: Africa Internet usage and 2015 population stats. Accessed online 26-10-2015 http://www.internetworldstats.com/stats1.htm

Jung, J, et al. (2001). Internet connectedness and inequality: beyond the "Divide". SAGE. Accessed online 10/26/2013 athttp://crx.sagepub.com/content/28/4/507

Kalan, J. (2013). African youth hungry for connectivity. Africa Renewal. Accessed online 26-10-2015 at http://www.un.org/ africarenewal/magazine/may-2013/african-youth-hungry-connectivity.

King, S. (2015). Which Nigerian tech startup will be worth a billion dollars soon? Accessed online 28-10-2015 at http:// radar.techcabal.com/t/which-nigerian-tech-startup-will-be-worth-a-billion-dollars-soon/2869.

Kling, R. (1996). Being read in cyberspace: boutique and mass media markets, intermediation, and the costs of on-line services. Communication Review, 1(3), 297-314.

Looker, E. D., \& Thiessen, V. (2003). Beyond the digital divide in Canadian schools: from access to competency in the use of information technology. Social Science Computer Review, 21(4), 487.

Manyika, J. A., et al. (2013). Lions go digital:tThe Internet's transformative potential in Africa. McKinsey Global Institute.

Matuluko, M. (2015). Meet Simeon Ononobi, the man behind simplepay; Nigeria's answer to paypal. Accessed online 28-102015 at http://techpoint.ng/2015/05/04/meet-simeon-ononobi-the-man-behind-simplepay-nigerias-answer-to-paypal/.

McLaren, D. (1999). Information and communications technologies. Australia: McLaren Technology Centre.

Miskoblog. (2014). PayPal now accepts Nigeria but see how you can enjoy the full benefits of a paypal account. Accessed online 27-10-2015 at http://www.miskoblog.com/paypal-now-accepts-nigeria-but-see-how-you-can-enjoy-the-fullbenefits-of-a-paypal-account.html.

Mossberger, K., et al. (2003). Virtual inequality: beyond the digital divide. Washington: Georgetown University Press.

Musimbi, K. R. A. (2002). Introducing feminist cultural hermeneutics: an African perspective. Sheffield: Sheffield Academic Press.

Nairaland.com. (2012). How to use paypal in Nigeria. Accessed online 27-10-2015 http://www.nairaland.com/173442/ how-use-paypal-nigeria/2.

Nairaland.com (2013). Get A Verified Paypal Account In Nigeria To Receive Funds. Accesed online 25/10/2015 http://www. nairaland.com/1392365/get-verified-paypal-account-nigeria.

Nairaland.com. (2015). Paypal response to my payment receiving complaint. Accessed online 27-10-2015 http://www. nairaland.com/2534003/paypal-response-payment-receiving-complaint.

Norris, P. (2001). Digital divide: civic engagement, information poverty, and the internet worldwide. New York: Cambridge University Press.

Nsehe, M. (2014). Paypal extends payment services to Nigeria, 9 other countries. Accessed online 23-10-2015 http://www. forbes.com/sites/mfonobongnsehe/2014/06/17/paypal-extends-payment-services-to-nigeria-9-other-countries/.

Olajide, K. (2014). TMAfrica catches up with funda to discuss the next generation e-learning platform in Africa. In TMAFRICA spotlight talks. Accessed online 26-10-2015 at http://www.tmafrica.net/blog/tmafrica-catches-up-withfunda-to-discuss-the-next-generation-e-learning-platform-in-africa/. 
Onodu, CO. (2013). Complete paypal solution for non paypal countries. Retrieved online 10/17/2013 at www.charleson. hubpages.com/hub/-onoduson.

Organization for Economic Co-orporation and Development (OECD) (2005). Innovation in science, technology and industry. Accessed online 10/28/2013 at http://www.oecd.org/sti/inno/innovationfordevelopment.htm.

Ozovehe, T. (2014). Paypal now in Nigeria but still can't pay for upgrade. Accessed online 27-10-2015 at https://en. forums.wordpress.com/topic/paypal-now-in-nigeria-but-still-cant-pay-for-upgrade.

Pepper, R., \& Garrity, J. (2015). ICTs, income inequality, and ensuring inclusive growth. In S. Dutta, T. Geiger, \& B. Lanvin (Eds.), The global information technology report 2015: ICTs for inclusive growth. Geneva: World Economic Forum.

Piragoff, D. (2005). Criminal misuse and falsification of identity -identity theft as a precursor to other crime. Tokyo: United Nations Asia and Far East Institute for the Prevention of Crime and the Treatment of Offenders.

Qiang, C. Z. W. (2009). IC4D: extending reach and increasing impact. World Bank: Economic impacts of broadband. Geneva.

Research, P. (2010). Millennials: confident. connected. Open to change. Washington: Pew Research Center Internet \& American Life Project.

Riessman, C. K. (1993). Narrative analysis. Newbury Park: Sage Publications.

Saghir, J. (2013). Cited in information and communication technology is revolutionizing development in Africa. Accessed online 10/22/2013 at http://www.worldbank.org/en/news/press-release/2012/12/10/information-communicationtechnology-revolutionizing-development-africa.

Seidler, N. (2013). An open internet in Africa: challenges shifting beyond. Accessed online 10/25/2013 at http://www. internetsociety.org/blog/2013/03/open-internet-africa-challenges-shifting-beyond-access.

Sobhy, A. (2014). Information activist Amr Sobhy shares his passion for civic engagement and a third millennium Africa of equal opportunity. In TMAFRICA spotlight talks. Accessed online 27-10-2015 at http://www.tmafrica.net/blog/ information-activist-amr-sobhy-shares-his-passion-for-civic-engagement-and-a-third-millennium-africa-of-equalopportunity-on-spotlight-talks/

Thierer, AD. (2000). Is the 'digital divide' a virtual reality? (Consumers' Research Magazine).

United Nations Economic and Social Council. (2015). Digital development: report of the secretary-general. Geneva: United Nations.

Van Dijk, J., \& Hacker, K. (2003). The digital divide as a complex, dynamic phenomenon. Geneva: The Information Society.

Ventures Africa. (2015). Nigeria is PayPal's second largest market in Africa. Accessed online 27-10-2015 at http:// venturesafrica.com/nigeria-is-paypals-second-largest-market-in-africa/.

Witte, J. C., \& Mannon, S. E. (2010). The Internet and social inequalities. New York: Routledge.

World Bank. (2012). Information and communication technology is revolutionizing development in Africa. Accessed online 10/21/2013 www.worldbank.org/en/news/press-release/2012/12/10/information-communication-technologyrevolutionizing-development-africa.

Yonazi, E. et al. (2013). eTransform Africa: the transformational use of information and communication technologies in Africa. Accessed online 10/22/2013 http://siteresources.worldbank.org/ extinformationandcommunicationandtechnologies/Resources/282822-1346223280837/MainReport.pdf.

\section{Submit your manuscript to a SpringerOpen ${ }^{\circ}$ journal and benefit from:}

- Convenient online submission

- Rigorous peer review

- Immediate publication on acceptance

- Open access: articles freely available online

- High visibility within the field

- Retaining the copyright to your article

Submit your next manuscript at $>$ springeropen.com 